\title{
The genetic mechanism of sex determination in the androdioecious flowering plant, Datisca glomerata (Datiscaceae)
}

\author{
DIANA E. WOLF*, LOREN H. RIESEBERG \& STANLEY C. SPENCER $\dagger$ \\ Department of Biology, Indiana University, Bloomington, IN 47405 and †Rancho Santa Ana Botanic Garden, 1500 N. \\ College Avenue, Claremont, CA 91711, U.S.A.
}

\begin{abstract}
A series of experimental crosses was conducted to determine the genetic basis of sex determination in the androdioecious plant species, Datisca glomerata (Datiscaceae). Sex determination in $D$. glomerata appears to be controlled by at least two loci. Males are homozygous recessive at both loci, whereas hermaphrodites have at least one dominant allele at either locus. However, the problem of sex determination has not been entirely resolved, as there appear to be two different linkage distances between the two sex determining loci $(36 \pm 4.5 \mathrm{cM}$ and $6.7 \pm 1.5 \mathrm{cM}$ ). This was unexpected, and further studies will be conducted to determine the nature of this anomaly. This is the first report of the genetics of sex determination in an androdioecious plant.
\end{abstract}

Keywords: androdioecy, breeding system, Datisca glomerata, Datiscaceae, sex determination.

\section{Introduction}

Sex determination mechanisms in flowering plants are extremely diverse, ranging from simple chromosomal determination to cytoplasmic and polyfactorial determination. In dioecious plant populations, for example, sex determination can be through the possession of heterochromatic or nonheterochromatic sex chromosomes (reviewed by Westergaard, 1958), through sex chromosome dosage (e.g. Parker \& Clark, 1991) or through many unlinked autosomal loci (e.g. Louis, 1989). However, the possession of a single sex-determining locus or chromosome seems to be the predominant form of sex determination in dioecious plants (Westergaard, 1958; Richards, 1986).

The genetic control of sex in gynodioecious populations has also been studied in detail and is quite different from that of dioecious populations. Three mechanisms have been identified: cytoplasmic male sterility (CMS), cytonuclear interactions and simple nuclear inheritance. Cytonuclear control is probably the most common form of sex determination in gynodioecious plants (Frank, 1989). Sometimes there are several different male sterile cytoplasms, along with several nuclear male restorers (e.g. Van

\footnotetext{
${ }^{*}$ Correspondence. E-mail: dewolf@bio.indiana.edu
}

Damme \& Van Delden, 1982; Van Damme, 1983).

The genetics of sex determination for other plant breeding systems have received less attention. In particular, the genetic basis of sex determination of an androdioecious plant has not previously been described.

Androdioecy is a rare unsding system in which populations contain two sexes, males and hermaphrodites (co-sexes). In a functionally androdioecious population, hermaphrodites gain fitness through both male and female function, whereas males can only gain fitness through male function. It has been predicted that androdioecy is very unlikely to evolve from hermaphroditism (Lloyd, 1975; Charlesworth \& Charlesworth, 1978; Charlesworth, 1984), the most common plant breeding system. Charlesworth (1984) even suggested that functional androdioecy is unlikely to exist. In fact, most putative cases of (morphological) androdioecy are functionally dioecious (reviewed in Charlesworth, 1984), subdioecious (e.g. Anderson et al., 1988) or andromonoecious (e.g. Thompson et al., 1989). Nonetheless, functional androdioecy has been confirmed in several plant and animal taxa (reviewed in Swensen et al., 1996).

Datisca glomerata (Presl.) Baill. (Datiscaceae) is the best studied example of functional androdioecy in plants (Liston et al., 1990; Fritsch \& Rieseberg, 
1992; Rieseberg et al., 1992, 1993; Philbrick \& Rieseberg, 1994; Swensen et al., 1996). This paper describes the results from a series of experimental crosses that were conducted to determine the genetic basis of sex determination in Datisca glomerata, the first such study reported in an androdioecious plant. In addition to providing basic information regarding the genetic control of this rare reproductive system, knowledge of its mechanistic basis can lead to: (i) insights concerning the sequence of reproductive system evolution in the Datiscaceae (Rieseberg et al., 1992; Swensen et al., 1996); (ii) more accurate models of the evolution of androdioecy (Lloyd, 1975; Charlesworth, 1984); and (iii) a better understanding of the long-term evolutionary stability of androdioecy (Liston et al., 1990).

\section{Materials and methods}

\section{Study organism}

Datisca glomerata (Datiscaceae) is a tall, wind-pollinated, perennial angiosperm. It occurs in riparian habitats from Baja California, Mexico, to northern California, U.S.A. Males and hermaphrodites can be easily distinguished by flower morphology (Fig. 1), and male frequencies range from 0 to 0.42 (Liston $e t$ al., 1990; P. Morrell, personal communication). Populations are generally small, and range from 26 to 317 adults per population (Liston et al., 1990; $\mathrm{P}$. Morrell, personal communication). Seven years of observations for both natural and garden-grown plants provide no evidence that individuals change sex over time, and apomixis does not occur (Liston et al., 1990; Fritsch \& Rieseberg, 1992). Androdioecy in $D$. glomerata appears to have evolved from dioecy (Rieseberg et al., 1992; Swensen et al., 1996), and fitness of male and hermaphrodite plants appears to be equal in androdioecious populations, a condition necessary for the persistence of androdioecy (Fritsch \& Rieseberg, 1992; Philbrick \& Rieseberg, 1994).

\section{Plant materials and crossing design}

Datisca glomerata seeds were collected from Baughman Spring (BS), Cedar Springs Dam (CS), Tie Canyon I (TC) and the San Juan Picnic Area (SJ) in the autumn of 1990 and grown to maturity at the Rancho Santa Ana Botanic Garden, Claremont, CA [see Liston et al. (1990) for description of all populations except SJ]. The San Juan Picnic Area is located along Ortega Highway, Orange County CA,
U.S.A. It contained 11 hermaphrodites and two males.

To determine whether the male phenotype was dominant or recessive, nine large hermaphrodites were selfed, mated with a male (two different males were used) and crossed with another hermaphrodite (a different hermaphrodite father was used for each). Pollination was carried out as described in Rieseberg et al. (1993), except in this study all of the pollen for a single cross came from a single individual. All of the seeds resulting from the crosses were planted in the greenhouses of either Rancho Santa Ana Botanic Garden or Indiana University. Sex was determined at maturity. The progeny from the hermaphrodite $\mathrm{TC} 4$ are not reported here because labels differentiating crosses may have been confused while moving from California to Indiana. Not all of the crosses with each hermaphroditic mother were successful, so for most of the hermaphrodites only the results from one or two crosses are reported.

A second set of crosses was carried out on offspring resulting from the first set of crosses to determine the number of different male and hermaphrodite genotypes. If several hermaphrodites were pollinated by a single male, and all progeny sex ratios were the same, then one could conclude that there was a single hermaphrodite genotype. By contrast, if several different progeny ratios were observed, this would be evidence of multiple hermaphroditism genotypes. The same experiment could be applied to maleness by crossing several males with a single hermaphrodite. In this study, different flowers on two hermaphrodites were each pollinated by one of five different males, and six different hermaphrodites were pollinated by two males. The seeds resulting from these crosses were treated and scored in the same manner as above.

\section{Data analysis}

We compared the observed sex ratio from each cross to the sex ratios expected from one-locus, two-locus and three-locus genetic models (see Table 1 for expected sex ratios under each model) using Yates corrected chi-square tests (Zar, 1984). Two alleles per locus were assumed for all models. Models that clearly did not fit the data were not tested with chi-square tests (e.g. models in which maleness was dominant). Progeny arrays with fewer than 10 individuals were considered too small to give reliable information concerning parental genotypes, and were not included in the statistical analyses. 
Based on progeny sex ratios, we estimated the genotype of each parent plant under models where this was possible. This allowed us to determine if genotypes were consistent across generations and among different crosses using the same parent.

One locus As the data clearly indicated that hermaphroditism was not recessive, only the male recessive model was considered in detail.

Two loci If sex is determined by two loci with complete dominance, there are four possible ways in which the two loci can interact to give two pheno- types (Table 1). In the duplicate dominant genes model (DDG; Stansfield, 1983), the dominant alleles of both loci produce the same phenotype, with no cumulative effect. In other words, a dominant allele at either locus or at both loci $\left(A_{-} b b, a a B_{-}\right.$or $\left.A_{-} B_{-}\right)$ produces one phenotype. The other phenotype is produced only when both loci are homozygous recessive ( $a a b b$; Table 1$)$. The duplicate recessive genes model (DRG; Stansfield, 1983) allows the same phenotype to be produced when either locus or both loci are homozygous recessive $\left(a a B_{-}, A_{-} b b\right.$ or $a a b b)$. The alternative phenotype is produced when neither locus is homozygous recessive (Table

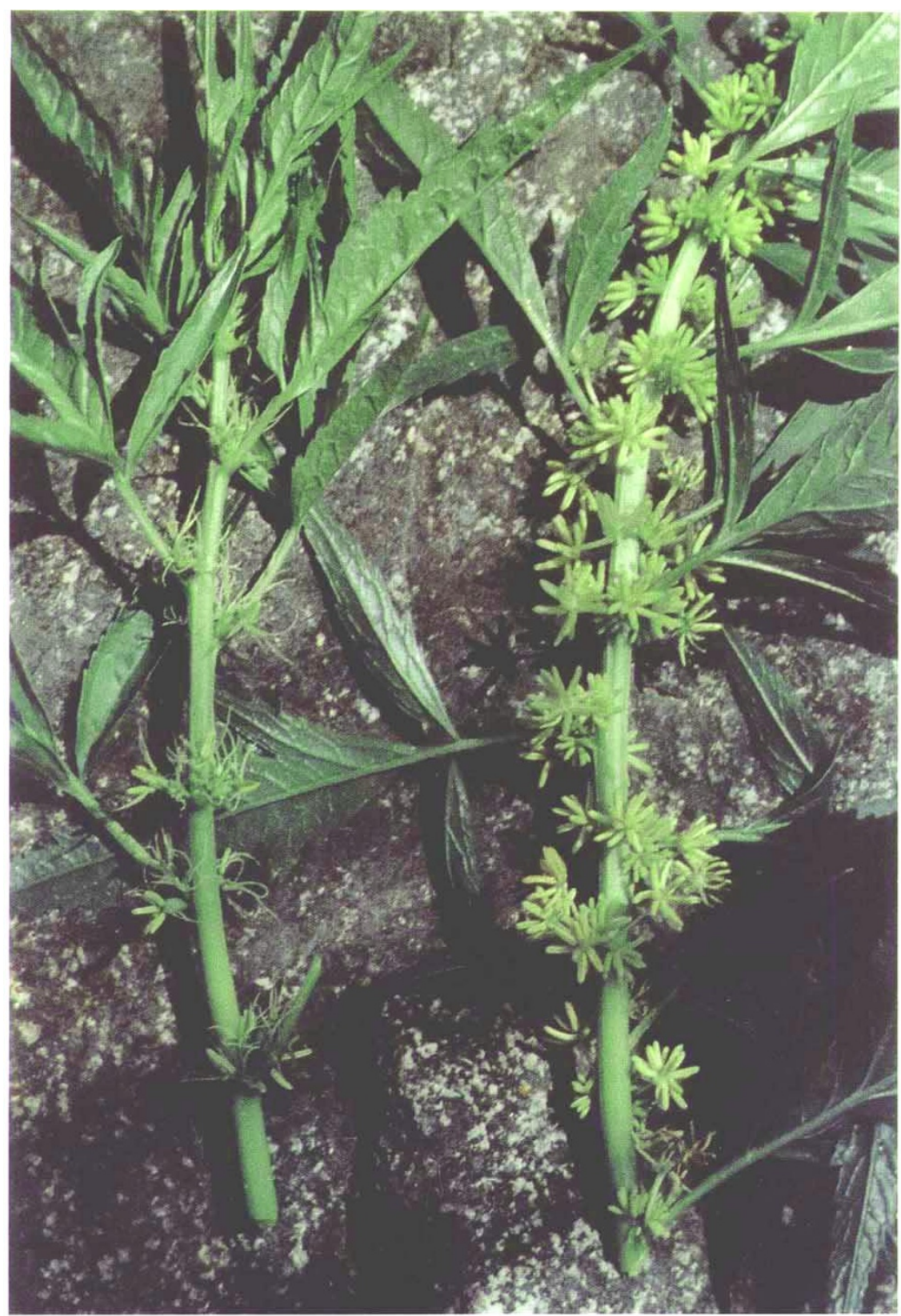

Fig. 1 Datisca glomerata hermaphrodites (left) are clearly distinguishable from males (right). The flowers of male plants produce more than three times as much pollen as the flowers of hermaphrodite plants (Philbrick \& Rieseberg, 1994). This, along with high outcrossing rates (Fritsch \& Rieseberg, 1992), allows the maintenance of androdioecy. 


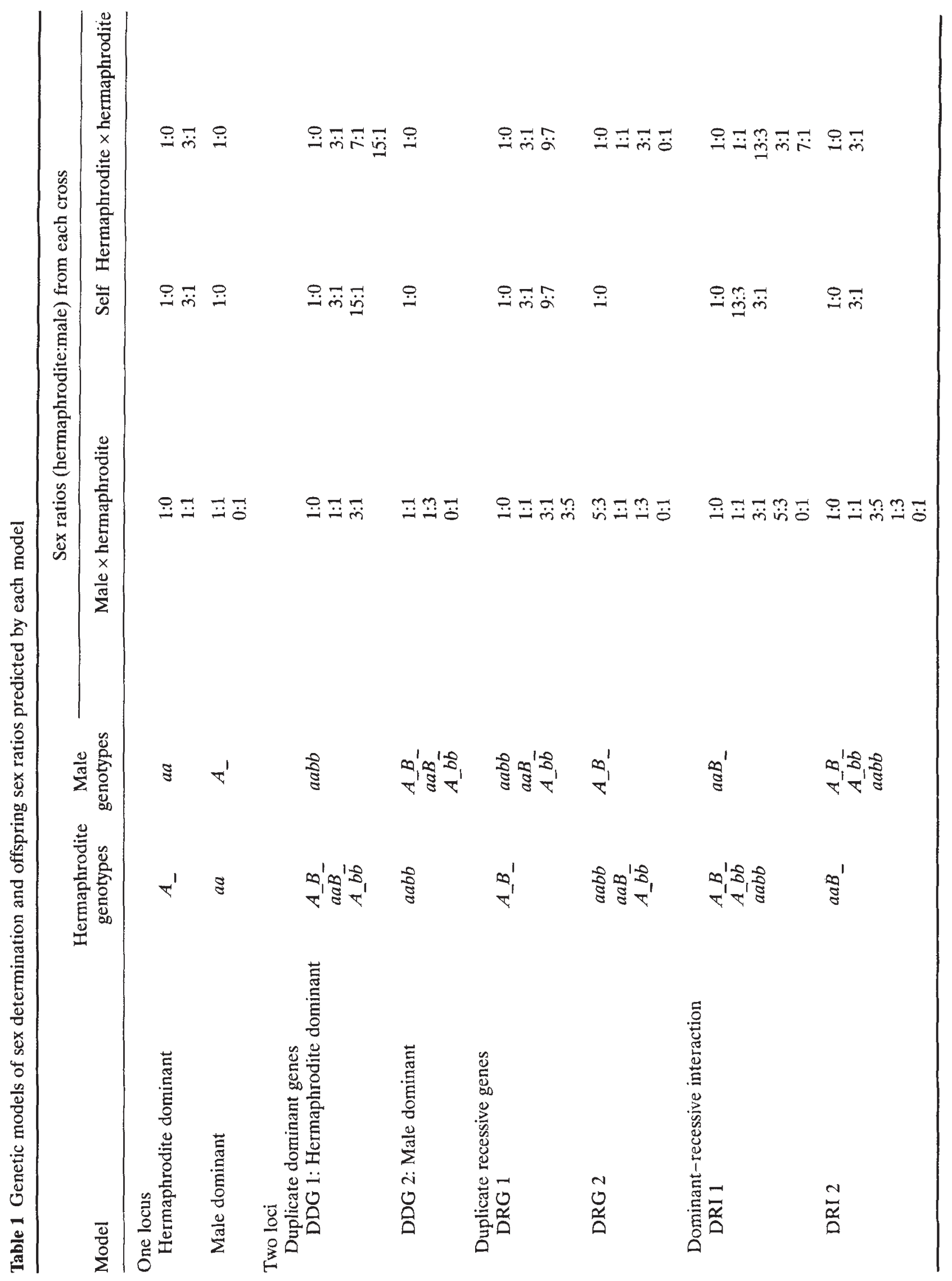

c) The Genetical Society of Great Britain, Heredity, 78, 190-204. 


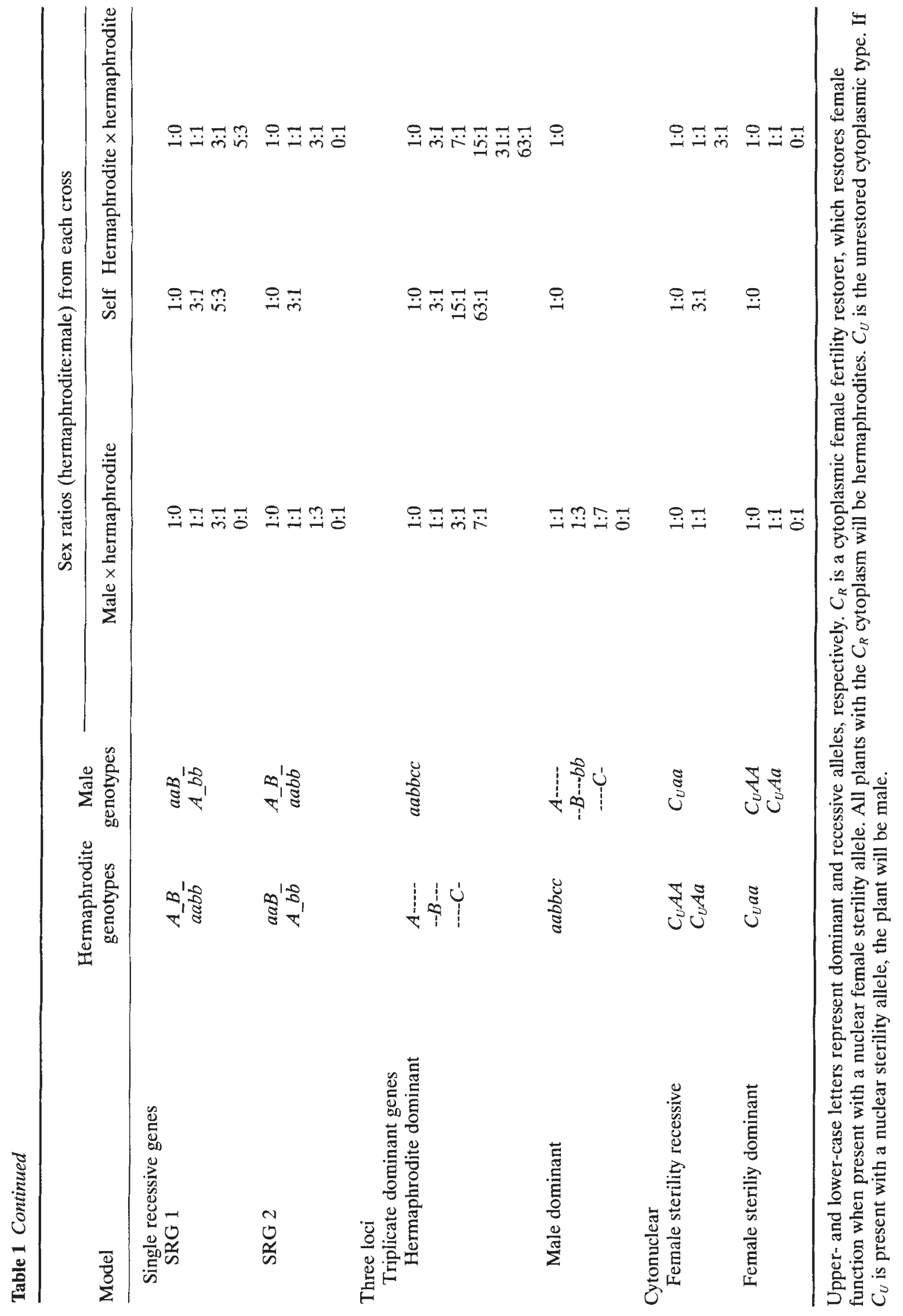

(C) The Genetical Society of Great Britain, Heredity, 78, 190-204. 
1). In the dominant and recessive interaction model (DRI; Stansfield, 1983), a dominant allele at one locus and a homozygous recessive genotype at the other locus $\left(a a B_{-}\right)$produces one phenotype, whereas all other combinations $(A B, A b b$ and $a a b b)$ produce the other phenotype (Table 1 ). The fourth type of interaction, the single recessive genes (SRG) model, allows phenotype one to be produced only when one locus is dominant and the other is recessive ( $a a B_{-}$or $\left.A_{-} b b\right)$. If both loci are dominant or recessive $\left(\bar{A}_{-} B_{-}\right.$or $\left.a a b b\right)$, the other phenotype is produced (Table $\overline{1}$ ).

Three loci Only the simplest three-locus model was considered (Table 1). Phenotype 1 is produced when a dominant allele is present at any of the three loci and phenotype 2 is produced only when all three loci are homozygous recessive.

Linkage If more than one locus is responsible for sex determination, linkage could influence the observed sex ratios. For each model, we determined if linkage could explain the deviations from expected ratios. If we assume the duplicate dominant genes model (DDG), we can calculate linkage distances between the two loci in a portion of the hermaphrodite $\times$ male crosses (Suzuki et al., 1989). If all linkage distances are similar, this provides support for the DDG model with linkage. If the linkage distances are highly variable, this suggests that the DDG model with linkage is flawed. Linkage distances could not be calculated for other two-locus models because both male and hermaphrodite phenotypes can be generated by multiple genotypes in these models. Therefore the number of progeny with parental and recombinant genotypes could not be determined.

Cytonuclear Two cytonuclear models were also considered (Table 1). Both models include two cytotypes and two nuclear alleles. One nuclear allele allows female fertility, whereas the other allele causes female sterility. Cytotype $C_{U}$ has no effect on the expression of the nuclear alleles, but $C_{R}$ restores female fertility if it occurs with a female-sterile nuclear genotype. In the first cytonuclear model, female sterility is dominant over female fertility. In the second cytonuclear model, female sterility is recessive. Both models assume that cytoplasmic inheritance is entirely maternal. It has been stated that female sterility cannot be cytoplasmically inherited (Lloyd, 1975), and this is probably true. However, a cytotype that restores female fertility can be maternally inherited, and should be able to invade a population that contains a nuclear female sterility allele.

\section{Results}

Crosses produced sex ratios that were (a) all hermaphroditic (1:0), (b) approximately 1:1 or (c) any ratio in between (Table 2). No significantly male-biased sex ratios were seen, suggesting that hermaphroditism is dominant to maleness. In three crosses, a few more males were produced than females. However, all of these ratios have a closer fit to the $1: 1$ sex ratio than to any other sex ratio that was possible in any of the models.

When different males pollinated the same hermaphrodite, all progeny arrays had similar sex ratios. Five different males each pollinated the hermaphrodites SJ1-M1 and CS1-H1. SJ1-M1 produced approximately $1: 1$ sex ratios in all five crosses, and the sex ratios are not significantly different from each other $\left(\chi_{4}^{2}=0.63, \mathrm{NS}\right)$. CS1-H1 produced 1:0 sex ratios in all five crosses. The other four hermaphrodites in the second generation were each pollinated by two different males. None of the mothers produced two progeny arrays with significantly different sex ratios (SJ1-S1: $\chi_{1}^{2}=0.10, \mathrm{NS}$; SJ2-S2: $\chi_{1}^{2}=0.03, \quad \mathrm{NS} ;$ TC1-M2: $\chi_{1}^{2}=0.03, \quad \mathrm{NS}$; TC4-M2: $\chi_{1}^{2}=0.16$, NS). However, when one male pollinated six different hermaphrodites, the sex ratios of progeny arrays produced by different hermaphrodites were significantly different (male SJ1-M2: $\chi_{5}^{2}=50.7, P<0.001$; male SJ2-S1: $\chi_{5}^{2}=43.9$, $P<0.001)$. The same was true when one male pollinated two different hermaphrodites (male TC1-M1: $\chi_{1}^{2}=14.15, \quad P<0.001 ;$ male TC4-M1: $\chi_{1}^{2}=32.93$, $P<0.001$; male BS1-H1: $\chi_{1}^{2}=29.42, P<0.001$ ). All of these values are highly significant even if a Bonferroni correction is applied $(\alpha=0.01)$. Thus, sex ratios were determined by the hermaphrodite used, and not the male.

Hermaphroditism appears to be dominant and only one genotype (recessive) produces males, so the four models with these characteristics (Table 1) are most likely to describe the genetics of sex determination: the one-locus, two-locus DDG, three-locus, and one of the cytonuclear models. The fit of the data to the models is described in Tables 2 and 3.

\section{One-locus: hermaphroditism dominant}

Twelve out of 22 crosses ( $\chi^{2}$-tests were only conducted on progeny arrays with at least 10 individuals) were significantly different from the expected ratios ( 8 out of 22 crosses were significantly different when 
| *

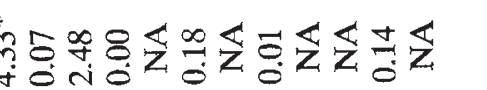

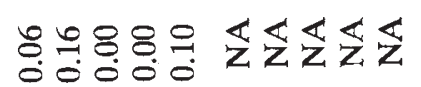

륭. 임

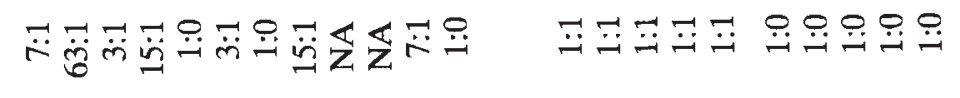
点

$* * *$

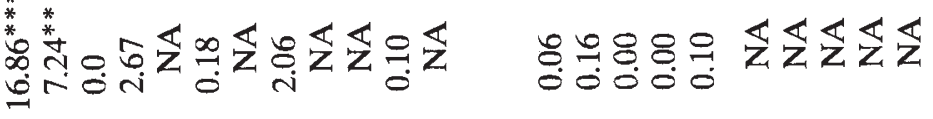

然

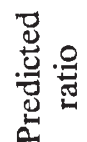

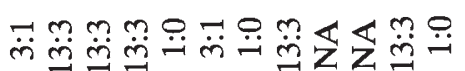

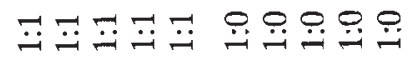

$* * *$

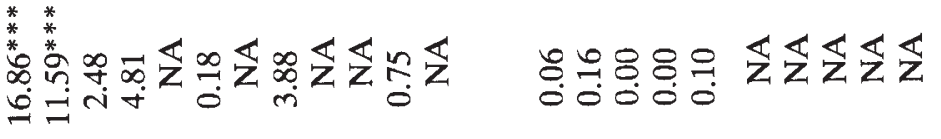

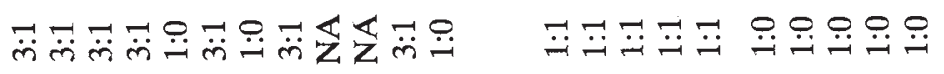

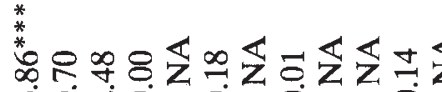

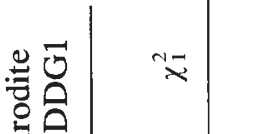

○ं

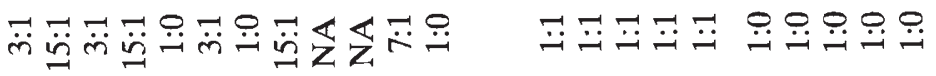

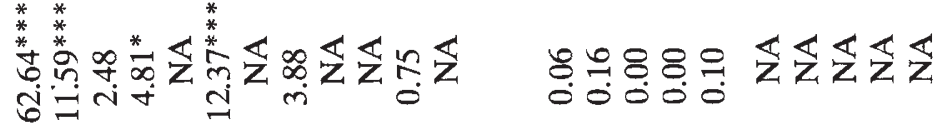
-

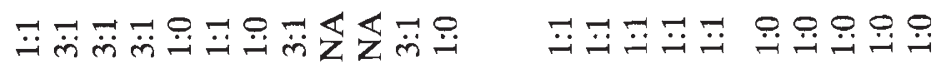

$m-4 \rightarrow 020-0 \rightarrow n$

mลกำก

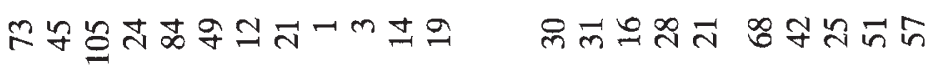

อิ

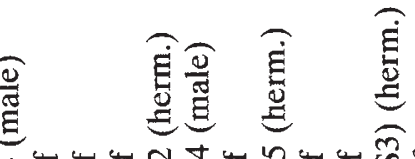

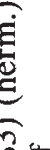

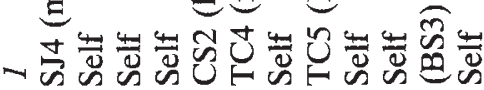
:

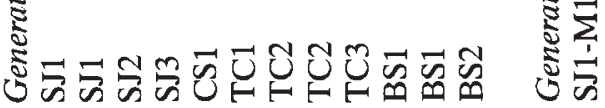

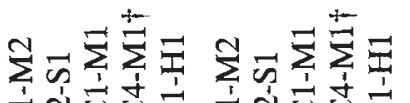

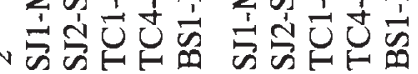

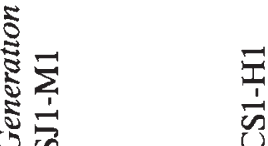




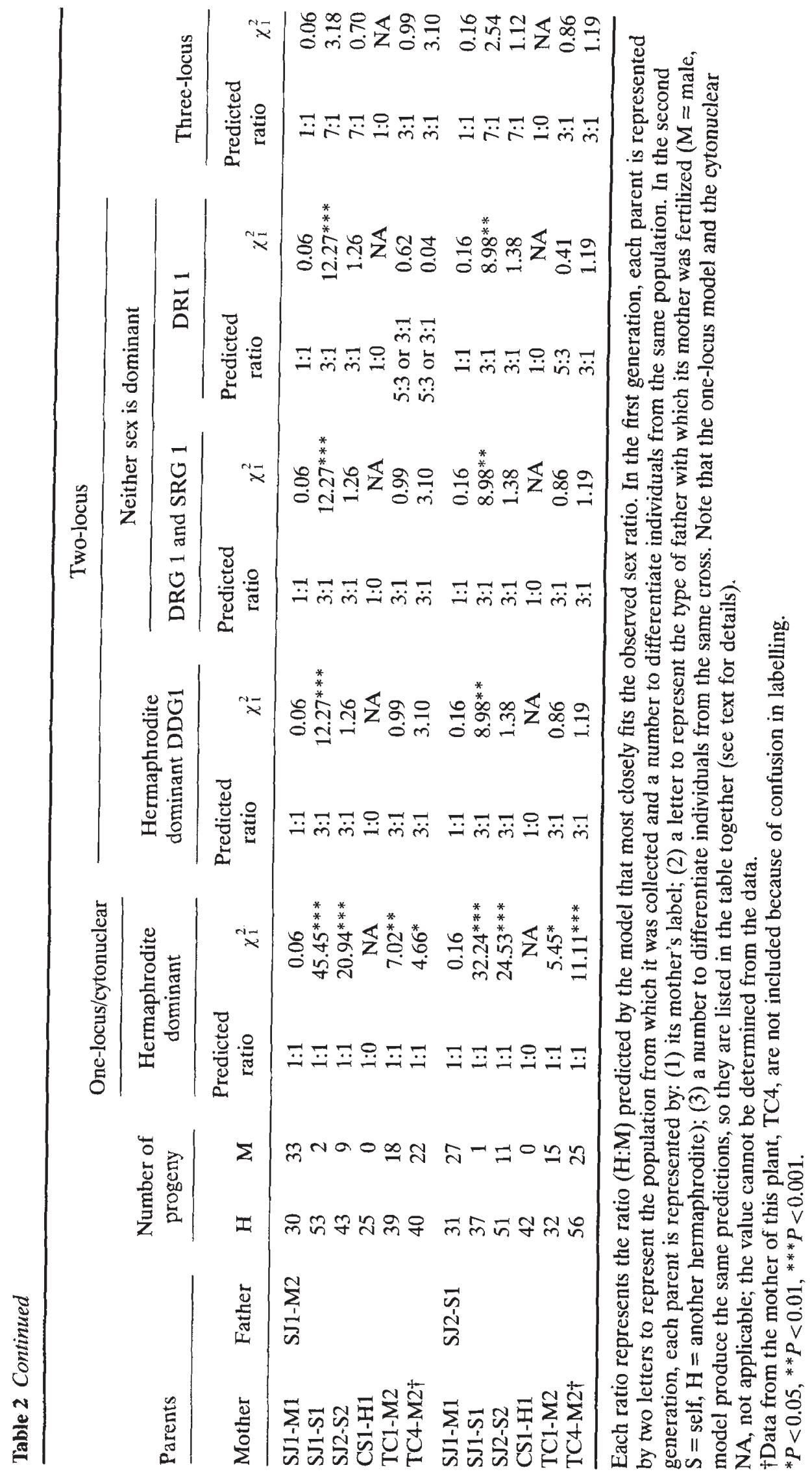




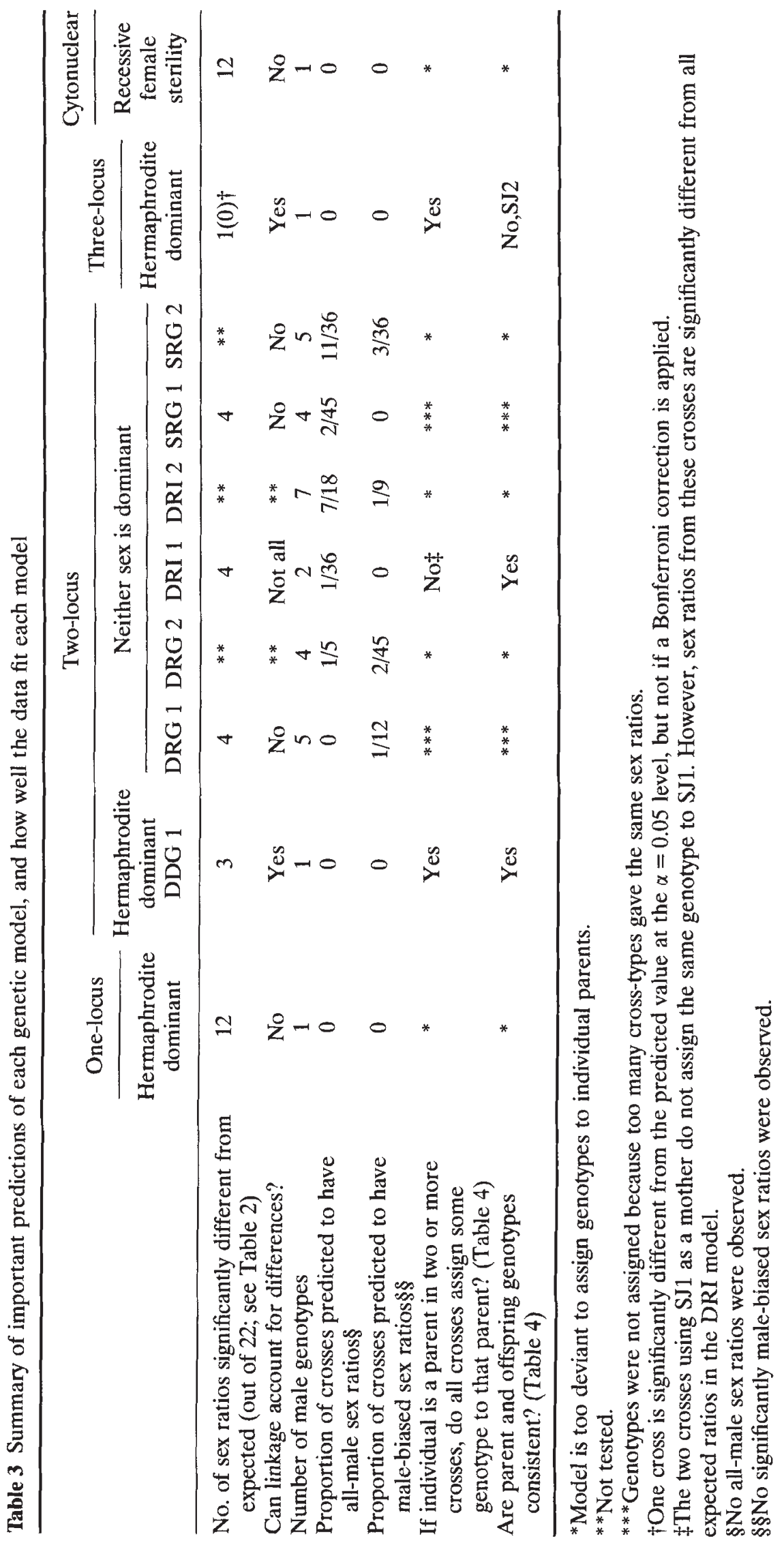

(C) The Genetical Society of Great Britain, Heredity, 78, 190-204. 
a Bonferroni correction was used, $\alpha=0.002$ ). This model is not supported by the data.

\section{Two-locus duplicate dominant genes (DDG): hermaphroditism dominant}

Only three out of 22 crosses had frequencies that were significantly different from expected $(P<0.01)$. The three deviating sex ratios were not independently produced; all were produced by mothers from the SJ population. Two of these were produced by the same mother (SJ1-S1) but by different sires. Thus, only two mothers produced deviant sex ratios. All of the significant and nonsignificant deviations could be accounted for if there was linkage between the two loci. Furthermore, estimates of maternal and paternal genotypes from progeny arrays are consistent for multiple crosses involving the same mother, as well as across multiple generations (Table 4). In other words, the inferred genotypes of second-generation parents were always consistent with the genotype of their known parents.

\section{$D D G$ with linkage: hermaphroditism dominant}

Assuming that there are two loci that interact as in the DDG model, we found that linkage distances are widely distributed. Linkage distances from seven crosses were quite large, ranging from 29 to $44 \mathrm{cM}$ $(36 \pm 4.5 \mathrm{cM}$; Table 4$)$, whereas the linkage distances from the remaining three crosses analysed were small, ranging from 5 to $8 \mathrm{cM}(6.7 \pm 1.5 \mathrm{cM})$. It is noteworthy that these are the same three crosses that deviated from expected sex ratios in the DDG model with no linkage. Although all of the crosses with short linkage distances are from the SJ population, not all mothers from SJ produced short linkage distances; the two crosses mothered by SJ2-S2 produced large linkage distances (Table 4).

\section{Three-locus: hermaphroditism dominant}

Only one cross deviates significantly $(P<0.05)$ from this model (Table 2). If one applies a Bonferroni correction, $\alpha=0.002$, this cross is no longer significantly different from expected. However, estimates of maternal genotypes from progeny sex ratios were not consistent across generations (Table 4). Under the three-locus model, the genotype of hermaphrodite SJ2-S2 was estimated as $A a B b C c$ or $A a B b c c$, and the genotype of its selfed parent, SJ2, was estimated as $A a b b c c$. An $A a b b c c$ parent could not have produced an $A a B b C c$ or $A a B b c c$ offspring when selfed. Thus, this model is considered less accurate than the two-locus DDG model.

\section{Cytonuclear model: female-sterility recessive}

This model predicts the same array of sex ratios as the one-locus model with dominant hermaphrodites (Table 1), so 12 out of 22 crosses were significantly different from expected (Table 2). Furthermore, there can be no linkage to account for skewed sex ratios. This model is rejected.

\section{Other models}

Because of the relatively small number of crosses made in this study, male-biased sex ratios could have been missed by chance. Therefore, although the data suggest that hermaphroditism is dominant to maleness, and that there is only one genotype that produces males, we should also consider models with more complex interactions among genes.

\section{Two-locus: duplicate recessive genes (DRG)}

In DRG 1, males can have five different genotypes (Table 1), whereas only one male genotype was detected in our study. In addition, for four out of 22 crosses, progeny sex ratios were significantly different from expectations (Table $2 ; P<0.01$ ). These deviations could not be accounted for by linkage. DRG 1 also predicts that one out of 12 crosses will be male-biased. As stated above, in the three crosses for which males outnumbered hermaphrodites, the data had a closer fit to a $1: 1$ ratio than to $3: 5$ or $1: 3$. The observed frequencies were significantly different from a $1: 3$ ratio in all three crosses, although only one of the three crosses was significantly different from a $3: 5$ ratio.

The fit to DRG 2 was even worse than the fit to DRG 1 . DRG 2 predicted that selfing would only produce all-hermaphrodite sex ratios. Overall, one out of five crosses should produce all-male sex ratios and two out of 45 crosses should produce malebiased sex ratios (Table 1). This model was rejected.

\section{Dominant and recessive interaction (DRI)}

DRI 1 predicted two male genotypes, and that one out of 36 possible crosses would produce all-male sex ratios (Table 1). We observed no all-male sex ratios, but we carried out only 34 crosses. The same four progeny sex ratios that differed from expectations in the DRG 1 model differed significantly from predictions in this model (Table $2 ; P<0.01$ ). Loose 


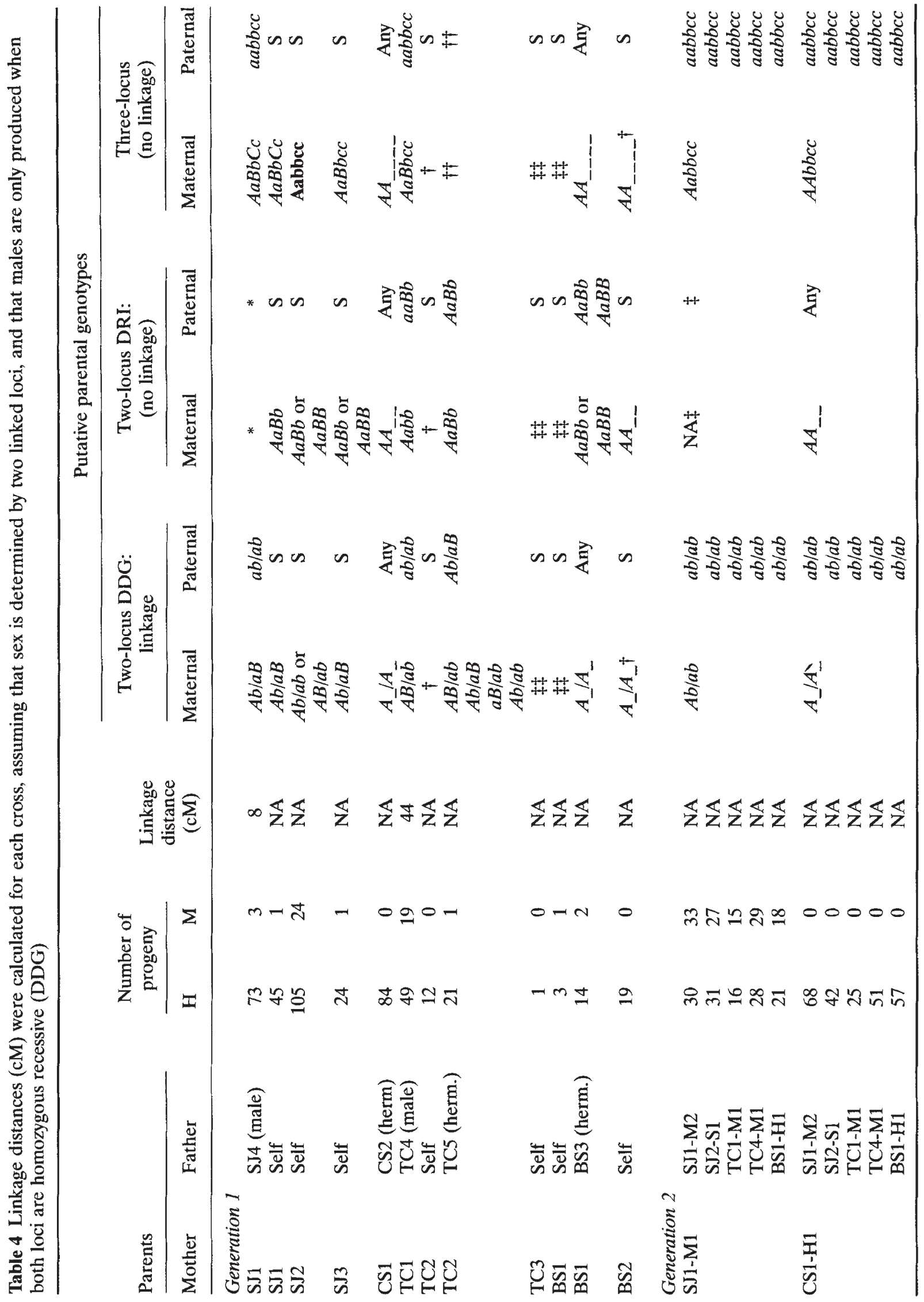




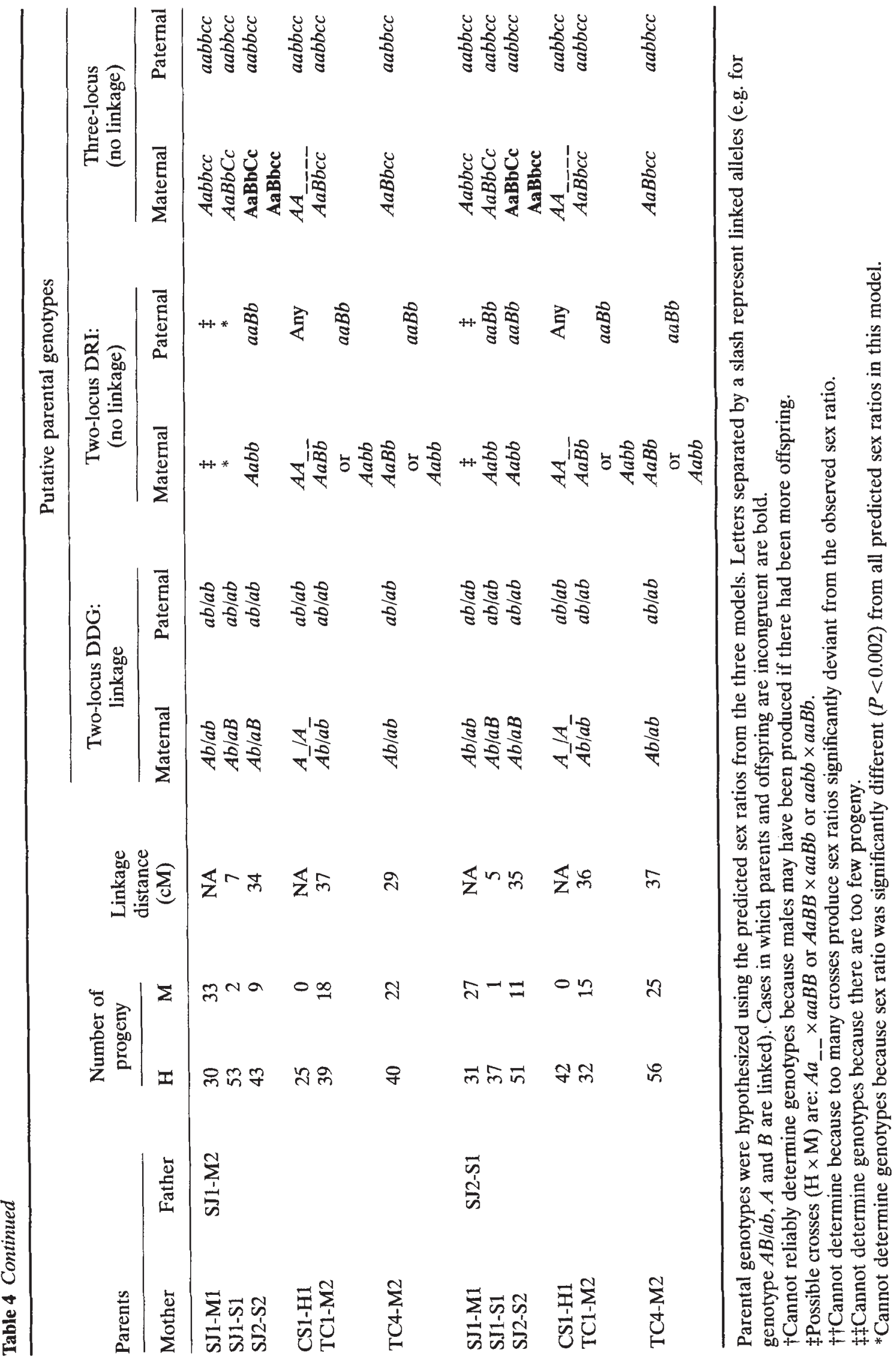


linkage could account for the deviations in hermaphrodite $\times$ hermaphrodite crosses but not in the hermaphrodite $\times$ male crosses. If we ignore crosses for which observed sex ratios differed significantly from expectations (e.g. progenies of SJ1), estimates of maternal and paternal genotypes are consistent for multiple crosses involving the same mother, as well as across multiple generations. However, progenies sharing $\mathrm{SJ} 1$ as a mother do not predict the same maternal genotype. This model has a poor fit.

DRI 2 can also be rejected, as it predicts seven male genotypes, and that seven out of 18 crosses should result in all males. In addition, one out of nine crosses should result in male-biased sex ratios.

\section{Single recessive genes (SRG)}

SRG 1 predicted four male genotypes (Table 1), and that two out of 45 possible crosses should produce only males. Four crosses (the same crosses as in DRG 1 and DRI 1) produced progeny sex ratios that differed from expectations (Table $2 ; P<0.01$ ). The deviations cannot be accounted for by linkage. SRG 2 predicted five male genotypes (Table 1), that 11 out of 36 sex ratios should be all-male, and that three out of 36 should be male-biased. SRG 2 can clearly be rejected.

\section{Discussion}

These data suggest that, in $D$. glomerata, hermaphroditism is dominant to maleness, all males in the study have the same genotype at the sex-determining loci and hermaphrodites have several different genotypes. However, this conclusion must be tempered by the fact that only two males were used in the first set of crosses, so dominant maleness alleles may have been present in one or more of the populations and missed by chance. Furthermore, the number of crosses was small, so by chance we may have failed to make a cross that would have produced malebiased sex ratios, or that would have caused a single hermaphrodite to produce progeny arrays with different sex ratios when fertilized with different males. However, given the data it seems unlikely that more than a few male genotypes exist, and there are certainly more hermaphrodite genotypes than there are male genotypes.

None of the genetic models fits the data without flaw; however, the DDG model in which hermaphroditism is dominant at two loci appears to have the best fit. In three crosses, sex ratios were significantly different from expected sex ratios, however linkage can account for all of the significant and nonsignificant differences from expectations. This is not true for any of the other models except for the threelocus model, which has other problems. The only problem with the DDG model with linkage is that linkage distances do not appear to be the same for all crosses (Table 4). A number of phenomena could be causing this anomaly besides an actual linkage distance polymorphism. These include meiotic drive (Carvalho \& Klaczko, 1994) and a maternally inherited factor in the SJ population that skews sex ratios, such as the male-killing (Hurst, 1993) and feminizing parasites (Juchault et al., 1994).

Because of the linkage distance polymorphism, further studies will be required to verify this hypothesis of gene action. We plan to identify random amplified polymorphic DNA (RAPD) markers (Williams et al., 1990) that are linked to the sex-determining loci. This will provide more conclusive evidence as to the number of polymorphic loci, and linkage distances between loci. It will also help us determine if meiotic drive or disproportionate death of males is occurring.

\section{Comparison with other species}

Although the sex determination systems of androdioecious plants have not been previously studied, sex determination systems are known in two androdioecious animals. In Caenorhabditis elegans, hermaphrodites have two $\mathrm{X}$ chromosomes, whereas males have only one X (Chitwood \& Chitwood, 1974). Sex determination in the conchostracan shrimp Eulimnadia texana is controlled by one nuclear locus; males are homozygous recessive and hermaphrodites can be heterozygous or homozygous for the dominant allele (Sassaman \& Weeks, 1993). Sex determination in $D$. glomerata is more complex than in both of these species.

Genetic and environmental factors affecting sex determination have been recently reported for the plant Mercurialis annua, which has been described as androdioecious (Pannell, 1997). However, the species does not fit a strict definition of androdioecy, as populations do not consist of males and co-sexes, but have two co-sexual genotypes: strict co-sexes and labile plants that produce either male or male and female flowers, depending on plant density. According to Lloyd (1980), there is a distinction between sex determination and gender determination. Sex is genetically determined, and possible sexes include male, female and co-sex. Gender is determined by the other plants in the population or by the environment.

(c) The Genetical Society of Great Britain, Heredity, 78, 190-204. 
Rieseberg et al. (1992) predicted that males would be heterogametic in $D$. glomerata. This is because phylogenetic evidence suggests that androdioecy in D. glomerata evolved from dioecy (Rieseberg et al., 1992; Swensen et al., 1996). If $D$. glomerata was derived from a dioecious species with heterogametic males, such as its nearest relative, $D$. cannabina (Sinoto, 1929), then D. glomerata males should also be heterogametic. The fact that sex determination in D. glomerata did not match the prediction shows that the evolution of sex determination is not as simple as one might expect.

It is interesting to note that recessive maleness alleles such as those found in D. glomerata should be maintained at twice the frequency of dominant maleness alleles, and thus are less likely to be stochastically eliminated than dominant maleness alleles. Populations of $D$. glomerata are frequently very small, and males are missing in some populations (Liston et al., 1990; P. Morrell, personal communication), so the recessive nature of maleness may have played a role in allowing androdioecy to persist in D. glomerata.

Another important way in which the sex determination system of $D$. glomerata differs from that of $D$. cannabina and most other dioecious plants is in the number of genetic factors involved in sex determination. In most dioecious species, sex is determined by a single locus or sex chromosome (Westergaard, 1958; Bull, 1983), but D. glomerata may have at least two sex-determining loci. A model by Charlesworth \& Charlesworth (1978) shows that, if dioecy is to evolve from gynodioecy, a female-sterility allele can invade a population only if it is closely linked to the male sterility locus. If they are not closely linked, hermaphrodites and neuters will be produced. It is also thought that sex chromosomes differentiate in order to prevent recombination between male sterility and female sterility loci (Bull, 1983). However, in an androdioecious system, recombination between two female sterility loci will not produce neuters, so there should be no linkage constraint. On the other hand, a two-locus system in which both recessive alleles are necessary for maleness should decrease the long-term stability of androdioecy, because males will be lost if the recessive allele is lost at either locus.

In conclusion, sex determination in the androdioecious plant $D$. glomerata appears to be controlled by at least two nuclear loci. Males are homozygous recessive at both loci, whereas hermaphrodites have at least one dominant allele at either locus. However, the mechanism of sex determination in this species is not entirely clear, as there appear to be two different linkage distances between the two sex-determining loci. This is unexpected, and further studies will be conducted to determine the nature of this anomaly. This is the first report of the genetics of sex determination in an androdioecious plant, and we suggest that the recessive nature of female sterility may be important in the stability of androdioecy. We plan to use our knowledge of sex determination in $D$. glomerata to create a genetically based model of the long-term maintenance of androdioecy under different sex determination systems.

\section{Acknowledgements}

We wish to thank Lynda Delph and Naoki Takebayashi for helpful discussions, Jeannette Whitton, Peter Morrell and Paula Kover for useful comments on the manuscript, and Peter Morrell for allowing us to cite his unpublished data.

\section{References}

ANDERSON, A. B., OVERAL, w. L. AND HENDERSON, A. 1988. Pollination ecology of a forest-dominant palm (Orbignya phalerata Mart.) in northern Brazil. Biotropica, 20, 192-205.

Bull, J. J. 1983. Evolution of Sex Determining Mechanisms. Benjamin/Cummings Publishing Co., Menlo Park, CA.

CARVAlho, A. B. D. AND KLACZKo, L. B. 1994. Y-linked suppressors of the sex-ratio trait in Drosophila mediopunctata. Heredity, 73, 573-579.

CHARlesworth, B. AND Charlesworth, D. 1978. A model for the evolution of dioecy and gynodioecy. Am. Nat., 112, 975-997.

Charlesworth, D. 1984. Androdioecy and the evolution of dioecy. Biol. J. Linn. Soc., 23, 333-348.

CHITWOOD, B. G. AND CHITwOOD, M. G. 1974. An Introduction to Nematodology (revised). University Park Press, Baltimore.

FRANK, S. A. 1989. The evolutionary dynamics of cytoplasmic male sterility. Am. Nat., 133, 345-376.

FRITSCH, P. AND RIESEBERG, L. H. 1992. High outcrossing rates maintain male and hermaphrodite individuals in populations of the flowering plant Datisca glomerata. Nature, 359, 633-636.

HURST, L. D. 1993. The incidences, mechanisms and evolution of cytoplasmic sex ratio distorters in animals. $J$. Parasitol., 54, 241-248.

JUCHAULT, P., FRELON, M., BOUCHON, D. AND RIGAUD, T. 1994. New evidence for feminizing bacteria in terrestrial isopods: Evolutionary implications. C. r. Acad. Sci. Serie III Sciences de la Vie, 317, 225-230.

LISTON, A., RIESEBERG, L. H. AND EliAs, T, S. 1990. Functional androdioecy in the flowering plant Datisca glomerata. Nature, 343, 641-642. 
LLOYD, D. G. 1975. The maintenance of gynodioecy and androdioecy in angiosperms. Genetica, 45, 325-339.

LLOYD, D. G. 1980. Sexual strategies in plants III. A quantitative method for describing the gender of plants. N. Z. J. Bot., 18, 103-108.

LOUIS, J. P. 1989. Genes for the regulation of sex differentiation and male fertility in Mercurialis annua L. $J$. Hered., 80, 104-111.

PANNELL, J. 1997. Mixed genetic and environmental sex determination in an androdioecious population of Mercurialis annua. Heredity, 78, 50-56.

PARKER, J. S. AND ClARK, M. s. 1991. Dosage sex-chromosome systems in plants. Plant Sci. (Limerick), 80, 79-92.

PHILBRICK, C. T. AND RIESEBERG, L. H. 1994. Pollen production in the androdioecious Datisca glomerata (Datiscaceae): Implications for breeding system equilibrium. $\mathbf{P l}$. Sp. Biol., 9, 43-46.

RIESEBERG, L. H., HANSON, M. A. AND PHILBRICK, C. T. 1992. Androdioecy is derived from dioecy in Datiscaceae: evidence from restriction site mapping of PCR-amplified chloroplast DNA fragments. Syst. Bot., 17, 324-336.

RIESEBERG, L. H., PHILbRICK, C. T., PACK, P. E., HANSON, M. A. AND FRITSCH, P. 1993. Inbreeding depression in androdioecious populations of Datisca glomerata (Datiscaceae). Am. J. Bot., 80, 757-762.

SASSAMAN, C. AND WEeKs, s. C. 1993. The genetic mechanism of sex determination in the conchostracan shrimp Eulimnadia texana. Am. Nat., 141, 314-328.

sinoto, Y. 1929. Chromosome studies in some dioecious plants, with special reference to allosomes. Cytologia, 1, 109-191.

StAnsfield, w. D. 1983. Theory and Problems of Genetics. McGraw-Hill, New York.

SUZUKI, D. T., GRIFFITHS, A. J. F., MILLER, J. H. AND LEWONTIN, R. C. 1989. An Introduction to Genetics. W. H. Freeman \& Co., New York.

SWENSEN, S. M., LUTHI, J. N. AND RIESEBERG, L. H. 1996. The sequence of reproductive system evolution in the Datiscaceae reexamined. Syst. Bot. (in press).

THOMPSON, J. D., SHIVANNA, K. R., KENRICK, J. AND KNOX, R. B. 1989. Sex expression, breeding system, and pollen biology of Ricinocarpus pinifolius: a case of androdioecy? Am. J. Bot., 76, 1048-1059.

VAN DAMme, J. M. M. 1983. Gynodioecy in Plantago lanceolata L. II. Inheritance of three male-sterility types. Heredity, 50, 253-273.

VAN DAMME, J. M. M. AND VAN DELDEN, w. 1982. Gynodioecy in Plantago lanceolata L. I. Polymorphism for plasmon type. Heredity, 49, 303-318.

WESTERGAARD, M. 1958. The mechanism of sex determination in dioecious flowering plants. Adv. Genet., 9, 217-281.

WILLIAMS, J. G. K., KUBELIK, A. R., LIVAK, J., RAFALSKI, J. A. AND TINGEY, s. v. 1990. DNA polymorphisms amplified by arbitrary primers are useful as genetic markers. Nucl. Acids Res., 18, 6531-6535.

Zar, J. H. 1984. Biostatistical Analysis. Prentice-Hall, Englewood Cliffs, NJ. 